\title{
REGIONAL DISPERSION OF INDEPENDENT PROFESSIONALS IN PRIMARY HEALTH CARE IN THE NETHERLANDS
}

\author{
L. Hingstman and H. Boon \\ Netherlands Institute of Primary Health Care, P.O. Box 1568, 3500 BN Utrecht, The Netherlands
}

\begin{abstract}
One of the main objectives of Dutch Government policy on primary health care concerns equal regional dispersion of health care provisions. At this moment these provisions are geographically not equally distributed when measured in terms of the number of inhabitants per practising professional in primary health care. In this paper the current patterns of dispersion of five professional groups are described. The groups concerned are the general practitioners, dentists, physiotherapists, pharmacists and midwives. These patterns are mainly a consequence of market forces because the professionals have had the freedom to choose where to practise their profession until recently. These decisions are affected by the "place utility" of an area. In this paper place utility is conceived as being determinated by the opportunities of an area to earn a living and the amenities of an area as residential and living-environment. These concepts are operationalized by a set of independent variables. In order to understand the (differences between the) patterns of dispersion of the professional groups concerned multiple regressionanalysis has been used, of which the results are compared to the hypotheses formulated.
\end{abstract}

Key words-primary health care, regional dispersion, health professionals, the Netherlands

\section{INTRODUCTION}

One of the most important objectives of policy on Dutch health care is equal regional dispersion of health care provisions. This is not to say that there are serious problems of regional dispersion or accessibility in terms of public health. There are no indications that the supply of health care provisions doesn't fit the minimum requirements to guarantee public health or, in other terms, that (regional variation in) morbidity and mortality can be attributed to (regional variation in) the supply of health care provisions. In respect of those professions that demand a large population basis in order to provide an adequate income for the professional (i.e. obstetrics and dispensing of medicine), problems of accessibility could arise in thinly populated areas, which could affect public health. In these areas obstetrics and dispensing of medicine are taken care of by general practitioners.

The above policy objective is part of the overall Government policy on Dutch health care aimed at controlling the (increasing) total costs of health care. This policy is based on the (assumed) relation between the utilization of health care services and the supply of health care provisions. In this way controlling the costs may be achieved by controlling the supply of health care provisions, i.e. the intake of professionals. Since health care is collectively financed, such a policy should also consider the regional distribution of health care provisions for reasons of regional equity.

The Government wants to impose strict planning in order to achieve this objective. The Hospital Facilities Act has introduced planning in secondary health care. The act enables the Government to exercise a strong influence on the capacity and func- tioning of secondary health care facilities, (psychiatric) hospitals, nursing-homes and the like [1]. In primary health care however this is only partly the case.

A policy of new establishments of general practitioners has been operative since February 1986, and the intake of dentists and physiotherapists has been regulated by exempting the public health insurance funds $(70 \%$ of the Dutch population is publicly insured) from any obligation to enter into a contract with individual practitioners. Special legal arrangements governing the establishment of pharmacists in practice have been operative for a long time. These arrangements however only apply to members of the pharmacists' professional organization. The only demands made on midwives setting up in practice concern the accessibility of their practice-area.

Government interference in the establishment of practices on the part of (independent) professionals as described above is a recent development and has had a very limited impact thus far. Consequently the current supply and dispersion in the provision of primary health care is to a great extent a result of market forces. The professionals have had the freedom to choose where to practise their profession.

The central theme in this paper is the current regional dispersion of the five professional groups. In the first part the observed spatial patterns will be described, after which attention will be paid to factors which may possibly account for the regional differentiation. Our suppositions on the effect of the explanatory factors discerned have been tested by means of multiple regression analysis, the results of which are presented in the final section. This paper is based on a NIVEL study [2] conducted on the occasion of the symposium on Geography and Health Care organized by the Department of Geography of 


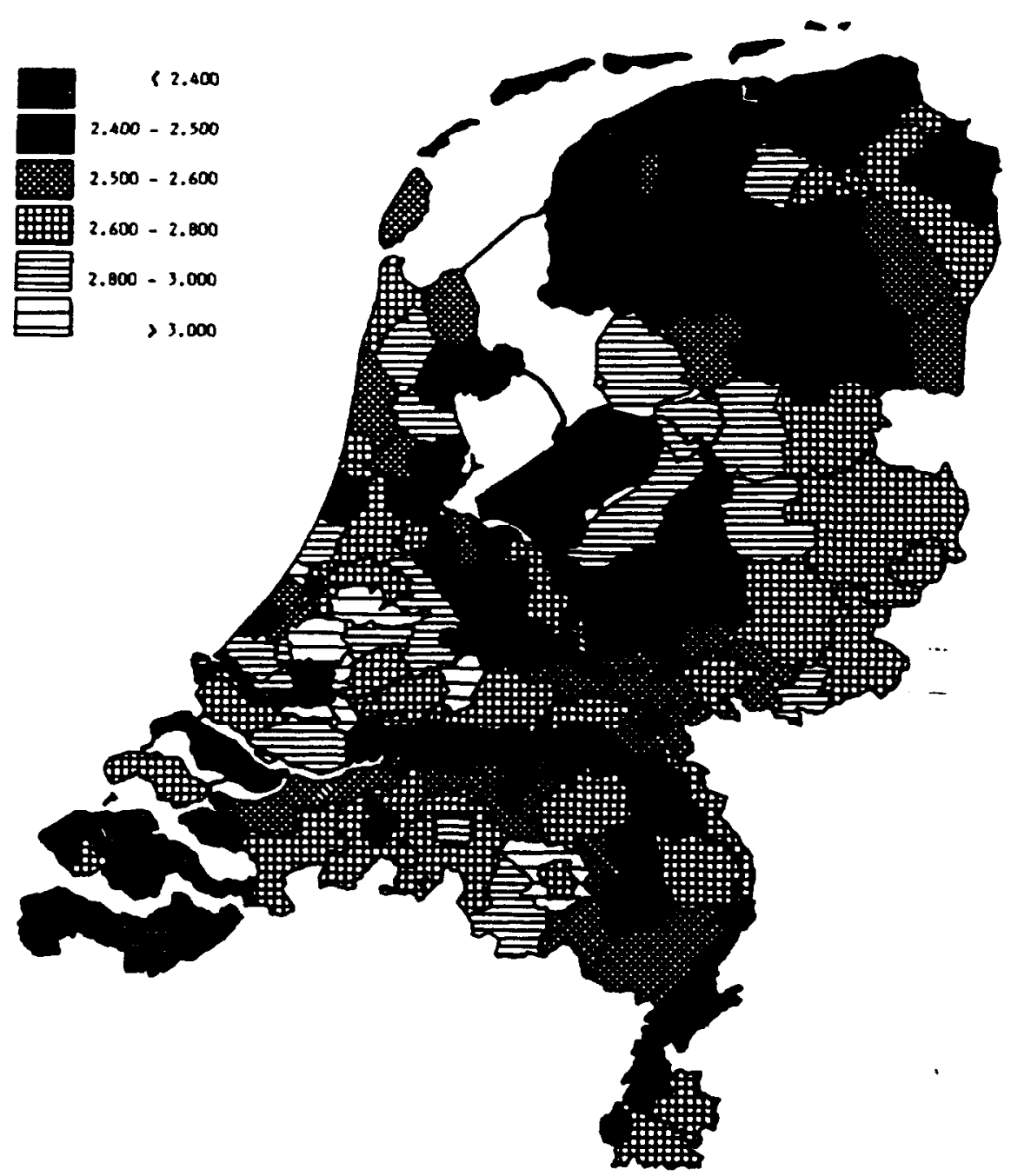

Fig. 1. 'General practitioner-density' (number of inhabitants per independently practising general practitioner) per economic geographic area (EGA) on 1 January 1984

the University of Utrecht in April 1986. However within the scope of this paper it is impossible to give a full account of analysis of the regional dispersion of five professional groups in primary health care. Where necessary, the study mentioned above is referred to.

\section{GEOGRAPHIC DISPERSION OF INDEPENDENT PROFESSIONALS}

\subsection{Patterns of dispersion}

In order to describe the dispersion of professionals in primary health care the number of professionals per economic geographic area (EGA)* has been related to the number of inhabitants per EGA. This implies the calculation of the number of inhabitants per general practitioner, dentist, physiotherapist, pharmacist and midwife for each EGA. Considering

*The Netherlands is subdivided in 129 EGA's, which are regions characterized by a high degree of intra-regional socio-economic homogeneity. the importance of part-time work in physiotherapy, the number of practising physiotherapists are calculated on the basis of full-time equivalents.

The pattern of dispersion for dentists and physiotherapists shows a clear similarity. For both groups high densities are observed in a belt running from the northern part of the 'Randstad' (i.e. the densely populated and urbanized western part of the Netherlands) via the central province of Utrecht to the central-eastern region of Arnhem (the more prosperous regions in the Netherlands). The general practitioners used to be characterized by the same pattern, but by now this pattern has disappeared. High densities for general practitioners occur in the north, in parts of the south and in urban zones. As an illustration of the patterns of dispersion, the regional distribution of general practitioners is shown in Fig. 1.

Dispersion of pharmacists is mainly characterized by high concentrations in and around the (large) towns. The small number of pharmacists in rural areas should not be taken to imply that these areas have no access to dispensing facilities. In these areas 
Table 1. Average, standard deviation and variation coefficient of the number of inhabitants per general practitioner, dentist, physiotherapist. pharmacist and midwife in the Netherlands (01/01/1984)

\begin{tabular}{lccc}
\hline & Average & $\begin{array}{c}\text { Standard } \\
\text { deviation }\end{array}$ & $\begin{array}{c}\text { Variation } \\
\text { coefficient }\end{array}$ \\
\hline General practitioner & 2571 & 285 & 0.11 \\
Dentist & 3237 & 993 & 0.28 \\
Physiotherapist & 2113 & 656 & 0.31 \\
Pharmacist & 17209 & 10044 & 0.58 \\
Midwife & 27300 & 12760 & 0.67 \\
\hline
\end{tabular}

medicine is generally dispensed by general practitioners with their own dispensary.

The pattern of dispersion for midwives is quite similar; that is to say high densities in urban zones and low densities in the countryside. In the latter areas obstetric care is largely provided by general practitioners. One might say that the distribution of primary health care facilities is rather unequal, though there are differences in this respect between the several professional groups as shown by the variation-coefficients in Table 1 . In terms of the similarities in dispersion, the professionals can be subdivided into three groups:

1. General Practitioners;

2. Dentists and physiotherapists;

3. Pharmacists and midwives.

How are these patterns of dispersion to be explained? We shall follow the research conducted by Groenewegen [3] in which location-choice and 'general practitioner-density' have been investigated. The central supposition in this study is that of regional differentiation under the heading of 'place utility'. In order to predict the patterns of dispersion for the professional groups we have to know which factors constitute the 'place utility' of a certain area. Groenewegen takes the line that 'place utility' is determined by three factors: the opportunity to earn a living, the amenities of an area as a residential and livingenvironment and the opportunity to keep up professional contacts. In this study the first factor turns out to be the most important in explaining general practitioners' location behaviour. The relevance of professional contacts was however not demonstrable. Professional contacts may possibly play a role for other professions but there are no appropriate data available on this subject. Consequently we have restricted ourselves to the first two utility-factors. In the formu- lation of hypotheses on the patterns of dispersion of the professional groups concerned, we may start with the assumption that there are no differences between the professional groups in their assessment of the factors of the residential and living-environment. Heida and Gordijn [4] were hardly able to demonstrate any differences between status-groups in their study of individual dwelling preferences. Although hypotheses on earning opportunities imply putting money first. we don't want to give the impression that this is the only motivation concerned.

\subsection{Earning opportunities}

The institutional structure of the health care system and in particular the rules governing professional fees determine to a large degree which characteristics of an area are relevant to income.

In the Netherlands, there are two systems of payment: payment on basis of service (fee for item system) and payment in the form of a fixed amount for each patient (capitation fee system).

Assuming that professionals seek to maximize their earnings, this can be achieved by carrying out more and better paid treatments in a fee for item system. In a capitation fee system this aim can be accomplished by increasing the number of registered patients [5]. There are important differences between the professional groups concerned in terms of pay (Table 2).

The differences mentioned above can be translated into differences between areas in terms of earning opportunities.

The number of practitioners per profession can be estimated on the basis of this data together with the population figures for the area.

In general the opportunities to increase the number of registered patients are best in densely populated areas. It is however not very attractive to register care-intensive patients (for instance elderly people in case of general practitioning). For professionals practising on a fee for item system, areas with a large demand for, and hence utilization of, their services are attractive, i.e. areas with a relatively high percentage of care itensive patients. It should be stressed that for different professions, care intensive patients are not the same. For instance, demand for (and utilization of dentists' services is highest among young people [6] whereas for physiotherapists' services it is highest among elderly people [7]. If 'private

Table 2. System of payment for independent professionals in primary health care

\begin{tabular}{|c|c|c|c|}
\hline & $\begin{array}{l}\text { Capitation fee } \\
\text { system }\end{array}$ & Fee for item system & $\begin{array}{l}\text { Difference in fee } \\
\text { between publicly and } \\
\text { privately insured } \\
\text { patients }\end{array}$ \\
\hline General practitioner & $\begin{array}{l}\text { Publicly insured } \\
\text { patients }\end{array}$ & $\begin{array}{l}\text { Privately insured } \\
\text { patients }\end{array}$ & Not relevant \\
\hline Dentist & & $\begin{array}{l}\text { Publicly and privately } \\
\text { insured patients }\end{array}$ & $\begin{array}{l}\text { Private fee much } \\
\text { higher }\end{array}$ \\
\hline Physiotherapist & & $\begin{array}{l}\text { Publicly and privately } \\
\text { insured patients }\end{array}$ & $\begin{array}{l}\text { Private fee slightly } \\
\text { higher }\end{array}$ \\
\hline Midwife & & $\begin{array}{l}\text { Publicly and privately } \\
\text { insured patients }\end{array}$ & No difference \\
\hline Pharmacist & $\begin{array}{l}\text { Publicly insured } \\
\text { patients (partly) }\end{array}$ & $\begin{array}{l}\text { Publicly insured } \\
\text { patients (partly) } \\
\text { Deliveries of medicine } \\
\text { to privately } \\
\text { insured patients }\end{array}$ & Not relevant \\
\hline
\end{tabular}


Table 3. Summary of hypotheses on relations between earning opportunities in areas and the geographical dispersion of professionals in primary health care

\begin{tabular}{|c|c|c|c|c|c|}
\hline \multirow[b]{2}{*}{ Earning opportunities } & \multicolumn{5}{|c|}{$\begin{array}{c}\text { Densities } \\
\text { (dependent variables) }\end{array}$} \\
\hline & $\begin{array}{c}\text { General } \\
\text { practitioners }\end{array}$ & Dentists & Physiotherapists & Pharmacists & Midwives \\
\hline Average income higher & - & + & + & \pm & - \\
\hline Percentage publicly insured higher & + & - & - & \pm & + \\
\hline Percentage aged people higher & - & - & + & + & - \\
\hline Birth rate higher & - & + & - & - & + \\
\hline Population density higher & \pm & + & + & + & + \\
\hline Level of urbanization higher & \pm & + & + & + & + \\
\hline Percentage general practitioners with obstetric practice higher & & & & & - \\
\hline Percentage general practitioners with dispensary higher & & & & - & \\
\hline Percentage women in childbearing age higher & & & & & + \\
\hline
\end{tabular}

+ , Positive relation; - , negative relation.

fees' are higher than 'public fees', earning opportunities are best in areas with relatively many publicly insured inhabitants. With respect to obstetric care and dispensing, the professionals concerned (midwives and pharmacists) may have to cope with 'competition' from general practitioners. In case of midwives this applies to privately insured patients, whereas in case of pharmacists this applies to thinly populated areas. In these areas general practitioners are allowed to dispense medicine; in more densely populated areas however they need a licence to do so (based on the act on the provision of medicine).

Table 3 gives an overall picture of all the hypotheses on the earning opportunities presented in the NIVEL-study. The signs indicate the direction of the expected relations. For further details and comments on the hypotheses formulated and accompanying references to the literature, the NIVEL-study [2] should be consulted.

\subsection{Residential and living-environment amenities}

A second factor that plays an important role in the choice of location among independent professionals is the attractiveness of an area as residential and living-environment. As we indicated before there is no reason to suppose differences in residential preferences between the professional groups involved. The central issue here is to investigate if and to what degree the attractiveness of an area is of explanatory value for the pattern of dispersion of the professional groups concerned. In the study by Groenewegen [3] heavily wooded areas with a low level of industrialization are considered attractive. A second factor in determining the attractiveness of an area is the distance to the nearest training centre. Most professionals will have left their parental home in order to live in rooms in the town where they were trained. During training students remain where they are being trained for a couple of years. After having completed their studies, most professionals will try to set up a practice in or in the vicinity of the training centre, because of relational networks built up during the period of

*We preferred the variable 'average income' to the variable 'percentage publicly insured' because the data on the latter refer only to inhabitants of municipalities in which there are more than two general practitioners. These data are hence not $100 \%$ reliable. The percentage publicly insured however is more or less a reflection of average income. study. For this reason, we consider the areas in the neighbourhood of training centres attractive for establishing a practice.

\section{METHOD OF RESEARCH}

As mentioned in Section 2.1. we have used the EGA's as geographic units of research. An important consideration behind this choice is the wide availability of appropriate data on this scale. Secondly, analysis dealing with primary health care provisions requires the use of rather small and homogeneous regions. Finally a sufficient number of units of research are required in order to apply current (statistical) techniques of analysis such as multiple regression analysis. The subdivision of the Netherlands into 129 EGA by the Central Bureau of Statistics fits the above requirements reasonably.

On the basis of the hypotheses formulated, 21 variables were entered in the analysis. The measurement values for these variables only refer to a particular moment in time (1/1/1984, unless indicated otherwise, see Appendix 1). The starting point of the analysis is that the current regional differentiation in the independent variables in general lines reflects the situation of 10-20 years ago. Cross-sectional analysis of current regional differentiation may therefore elucidate the location decisions of professionals in the past.

Before applying multiple regression-analysis, bivariate correlation analysis was used in order to trace possible (multi)collinearity.

The results of the bivariate correlation-analysis are shown in Appendix 1. On the basis of this analysis we have selected the following set of independent variables which are entered for all (unless otherwise indicated) five dependent variables discerned, i.e. densities of the five professional groups.

\section{Amenities:}

-percentage green belt/woodland

--distance to the nearest training centre (for the concerned profession)

\section{Earning opportunities:}

$$
\begin{aligned}
& \text {-average income } \\
& \text {-percentage of elderly people } \\
& \text { - birth-rate } \\
& \text { - population-density }
\end{aligned}
$$


competition general practitioners (only for midwives)

-presence of a (dispensing) general practitioner (on basis of the WOG, i.e. provision of medicine Act 1963, only for pharmacists).

\section{RESULTS}

The results of the multiple regression analysis on regional differences in the densities of the five professional groups are shown in Table 4.

To interpret the results one should be aware of the fact that the densities are measured in terms of the number of inhabitants per profession. This choice means that a negative $B$-value implies the negative influence of the independent variable on the number of inhabitants per professional and thus a positive influence on the density. The larger the number of inhabitants per professional, the lower the density and vice versa.

The main conclusions which can be drawn from the regression-analysis are as follows:

-The results with respect to regional differences in general practitioner and midwife-density are somewhat disappointing with 19.5 and $20.5 \%$ respectively explained variation. The results with regard to both professional groups should therefore be interpreted cautiously. The results for the dentists, physiotherapists and pharmacists are definitely satisfactory with respectively $59.6,46.6$ and $77.6 \%$ variation explained.

-For the dispersion of general practitioners the percentage, of elderly people and to a lesser extent the percentage of woodland and level of income are the most explanatory variables. The other variables are not significant. The relatively small percentage of the explained variation might well be due to the fact that there is little variation in general practitioner density at all (see Table 1). Assuming that 'if a phenomenon has little variation, there is little to explain' this would mean that this model is hardly fit to explain regional differentiation in general practitioner density. The results however correspond to findings from other research on location decisions of general practitioners [5].

-The pattern of dispersion for dentists is strongly affected by regional differentiation in average income and the percentage of elderly people. In addition, the attractiveness of an area (distance and percentage woodland) turns out to be a significant factor affecting dentists' choice of location.

-The physiotherapists are the only professional group among whom the distance to the nearest training centre plays a very important role. The (very) high B-value of this variable is probably due to the fact that educational facilities for physiotherapists are much more widespread than for the other professional groups (and hence increasing the relevance of this factor). For the rest, the physiotherapists show similar ties to the dentists.

- Competition from general practitioners is an important factor in explaining the regional differentation in midwife-density. Besides, as expected, the birth-rate turns out to be significant. In contrast to our expectations populationdensity is not significant. In this respect there might be a question of an indirect relation as a result of the competition-variable (percentage general practitioners with an obstetric practice). Obviously because of the low percentage of explained variation, some other factors also affect midwives' location decisions.

In contrast to general practitioners, the opportunities to keep up professional contacts possibly do play an important role. Unfortunately it is impossible to refer to other research in this field because it has, as far as we know, never been conducted till thusfar.

- The 'competition' variable plays an even more

Table 4. Results of the multiple regression analysis on the regional dispersion of the professional groups involved

\begin{tabular}{|c|c|c|c|c|c|}
\hline & \multicolumn{5}{|c|}{ B Values* on } \\
\hline & GP & Dent & Phys & Midw & Phar \\
\hline \multicolumn{6}{|l|}{ Earning opportunities } \\
\hline Average income & $\underline{0.227}$ & $=0.400$ & -0.215 & -0.012 & 0.019 \\
\hline Percent elderly people & -0.409 & -0.187 & -0.353 & -0.036 & -0.133 \\
\hline Birth rate & -0.123 & 0.162 & -0.131 & -0.314 & -0.046 \\
\hline Population density & 0.010 & $=0.364$ & -0.083 & 0.119 & 0.155 \\
\hline $\begin{array}{l}\text { Percent gencral practitioners } \\
\text { with dispensary }\end{array}$ & - & - & - & - & $\underline{0.976}$ \\
\hline $\begin{array}{l}\text { Percent general practitioners } \\
\text { with obstetric practice }\end{array}$ & - & - & - & $\underline{0.528}$ & - \\
\hline \multicolumn{6}{|l|}{ Amenities } \\
\hline Distance to nearest training centre & 0.170 & $\underline{0.155}$ & $\underline{0.434}$ & 0.039 & -0.070 \\
\hline Percent woodiand & -0.212 & $=0.177$ & $-\overline{0.106}$ & -0.245 & 0.054 \\
\hline Total variation explained & $19.5 \%$ & $59.6 \%$ & $46.6 \%$ & $20.5 \%$ & $77.6 \%$ \\
\hline
\end{tabular}

* B Values = standardized partial regression coefficients.

Underscored values are significant at 0.05 level.

$G P=$ General practitioner density (number of inhabitants per general practitioner)

Dent $=$ Dentist density (number of inhabitants per dentist)

Phys $=$ Physiotherapist density (number of inhabitants per physiotherapist)

Midw = Midwife density (number of inhabitants per midwife)

Phar = Pharmacist density (number of inhabitants per pharmacist). 
Table 5. Confrontation of expectations with the results of the multiple regression-analysis

\begin{tabular}{|c|c|c|c|c|c|c|c|c|c|c|}
\hline & \multicolumn{10}{|c|}{ Density $(1)$} \\
\hline & Exp.* & Res. ${ }^{+}$ & Exp. & Res. & Exp. & Res. & Exp. & Res. & Exp. & Res. \\
\hline $\begin{array}{l}\text { EARNING OPPORTUNITIES } \\
\text { average income higher }\end{array}$ & - & - & + & + & + & + & - & & \pm & \\
\hline percentage elderly people higher & - & + & - & + & + & + & - & & + & + \\
\hline birth rate higher & - & & + & & - & & + & + & - & \\
\hline $\begin{array}{l}\text { population density higher } \\
\text { percentage general practitioners with }\end{array}$ & \pm & & + & + & + & & + & & + & - \\
\hline $\begin{array}{l}\text { obstetric practice higher } \\
\text { percentage general practitioners with }\end{array}$ & $n r$ & & $\mathrm{nr}$ & & $\mathrm{nr}$ & & - & - & nr & \\
\hline dispensary higher & $\mathrm{nr}$ & & nr & & $n r$ & & $\mathrm{nr}$ & & - & - \\
\hline $\begin{array}{l}\text { AMENITIES } \\
\text { percentage woodland higher } \\
\text { distance to the nearest training centre higher }\end{array}$ & + & + & + & + & + & - & + & & + & \\
\hline
\end{tabular}

Exp = expectations

+ Res. = results regression-analysis

+ Variable contributes significantly in explaining $y$ in positive direction, - , variable contributes significantly in explaining $y$ in negative direction. Blank variable turns out to be insignificant. nr. not relevant.

important role in the case of the pharmacists. The inadequate economic basis of support for a pharmacists' practice in the areas in which general practitioners have their own dispensaries (i.e. in the countryside) underlies the strong explanatory value of this factor. Furthermore on the basis of the WOG (Provision of Medicines Act) the position of the pharmacists in the other (more densely populated) areas is more or less protected against competition from general practitioners. The other significant variable is the percentage of elderly people; i.e. the group offering the best source of income for pharmacists.

When compared to the hypotheses, as formulated in Section 2, the resuits described above are quite satisfactory. Table 5 gives an overall summary of the confrontation of the hypotheses formulated with the results of the multiple regression analysis.

\section{SUMMARY AND CONCLUDING REMARKS}

The geographical dispersion of professionals in primary health care in the Netherlands is a result of market forces. Restrictive regulations concerning the establishment of professionals have only been operative for a few years. The effect of these regulations on the pattern of dispersion as of 1984 however is negligible because of their recent character.

In respect of this pattern of dispersion the professional groups concerned may be subdivided in three groups, these are:

1. General practitioners with high densities in the north of the Netherlands and in urban zones.

2. Dentists and physiotherapists with high densities in a belt which runs from the northern part of the 'Randstad' via the central province of Utrecht to the central eastern region of Arnhem, in other words the more prosperous areas.

3. Midwives and pharmacists with high densities in urban zones and very low densities in rural areas.

One piece of research has shown that possible explanations of the location choice of professionals should be thought of in terms of the income opportunities and the amenities of an area. In order to understand the regional pattern of dispersion. multiple-regression analysis on the densities of the five professional groups has been used. We selected the percentage of woodland and the distance to the nearest training centre, as indicators for the attractiveness of an area. The income opportunities have been measured in terms of average income, percentage of elderly people. birth-rate, populationdensity and 'competition' from general practitioners in case of midwives and pharmacists. We used the economic geographic area (EGA) as a regional entity of research.

The results of the regression analysis have been compared with the hypotheses formulated, which are summarized in Table 5.

The results of the regression correspond fairly well to our expectations. Furthermore, they are certainly meaningful in the sense that the independent variables succeed in explaining a high percentage of the variation in the density of the professional groups. This applies in particular to physiotherapists, dentists and pharmacists (with about 47,60 and $78 \%$ variation explained) and to a lesser extent to general practitioners and midwives (both about 20\% variation explained).

What policy-implications do our findings have?

In the first place insight into the forces behind the current regional distribution of professionals might be useful to policy-makers involved in policies aimed at a better (more equal) regional distribution of health care provisions. Such policies may be 'direct', i.e. controlling the intake of professionals through legislative measures, such as 'establishment-licenses', to be issued by the (local) authorities. At the moment such a policy is operative on the intake of general practitioners. Another possibility is to steer the intake of professionals by encouraging establishment in areas with relatively few practising professionals and discouraging establishment in areas with a relatively large supply of the health care provision concerned The best way to do so is through the system of 
payment, particulary in the case of a fee for item system (and thus influencing earning opportunities). However, a policy based on a regionally differentiated system of payment might be very difficult to accomplish for practical reasons.

Research on policy decisions has shown that the regional distribution of both dentists and general practitioners has become more equal over the 1969-1979 period. Obviously regional inequality of both health care provisions has diminished on account of market forces, of which the increase in the number of both dentists and general practitioners is the most important. It will be interesting to see if and how far Government policies will succeed in (further) reducing regional differences. Finally the point should be stressed that perfect regional equality of health care provisions might not be desirable because of regional differentiation in demand for and utilization of health services, owing to factors rclated to morbidity such as age distribution, income level, education and the like. This would mean that optimum regional equality in the supply of (primary) health care provisions is not necessarily synonymous to regional equity. It is however very difficult to estimate which 'part' of regional inequality interferes the principle of regional equity and which part does not.

\section{REFERENCES}

1. Roscam Abbing E. W. Bouw en werking van de gezondheidszorg in Nederland (Structure and Functioning of
Dutch Health Care). Bohn. Scheltema \& Holkema. Utrecht/Antwerpen, 1983.

2. Hingstman $\mathrm{L}$. and Boon $\mathrm{H}$. Regionale spreiding van vrije beroepsbeoefenaren in de eerstelijnsgezondheidszorg (Regional Dispersion of Independent Professionals in Primary Health Care). NIVEL. Utrecht, 1986.

3. Groenewegen P. P. Vijfentwintig jaar vestigingen van huisartsen, deel II: regionale verschillen in huisartsendichtheid en veranderingen daarin. (twenty five years of establishing a practice by general practitioners. part II; regional differentiation in 'general practitioner density' and changes in time. Utrecht. NIVEL. 1985

4. Heida M. and Gordijn L. Regionale woontoorkeuren: verslag van een onderzoek naar de regionale woonvoorkeuren van huishoudens in Nederland. alsmede naar de factoren die aan deze woonvoorkeuren ten grondslag liggen. (Regional Residential Preferences: report of research on regional residential preferences of individual households and in addition on factors underlying these preferences). Planologisch Studiecentrum TNO, Delft, 1978

5. Groenewegen P. P. and J. van der Zee. De spreiding van huisartsen over Nederland; huisartsen en tandartsen vergeleken. (Regional dispersion of General Practitioners in the Netherlands: General Practitioners and Dentists compared). Utrecht, NHI, 1982.

6. Richards N. D. Utilization of dental services. In Social Sciences and Dentistry (Edited by Richards N. D. and Cohen L. K.). Den Haag, 1971.

7. Kerkhof A. M. M. and Groenewegen P. P. Enige gegevens over het gebruik van fysiotherapeutische zorg (Some data on the utilization of physiotherapatical provisions.) In De Eerstelijn Onderzocht. (Research on Primary Health Care). (Edited by Boerma W. G. W. and Hingstman L.) Van Loghum Slaterus, Deventer, 1985. 

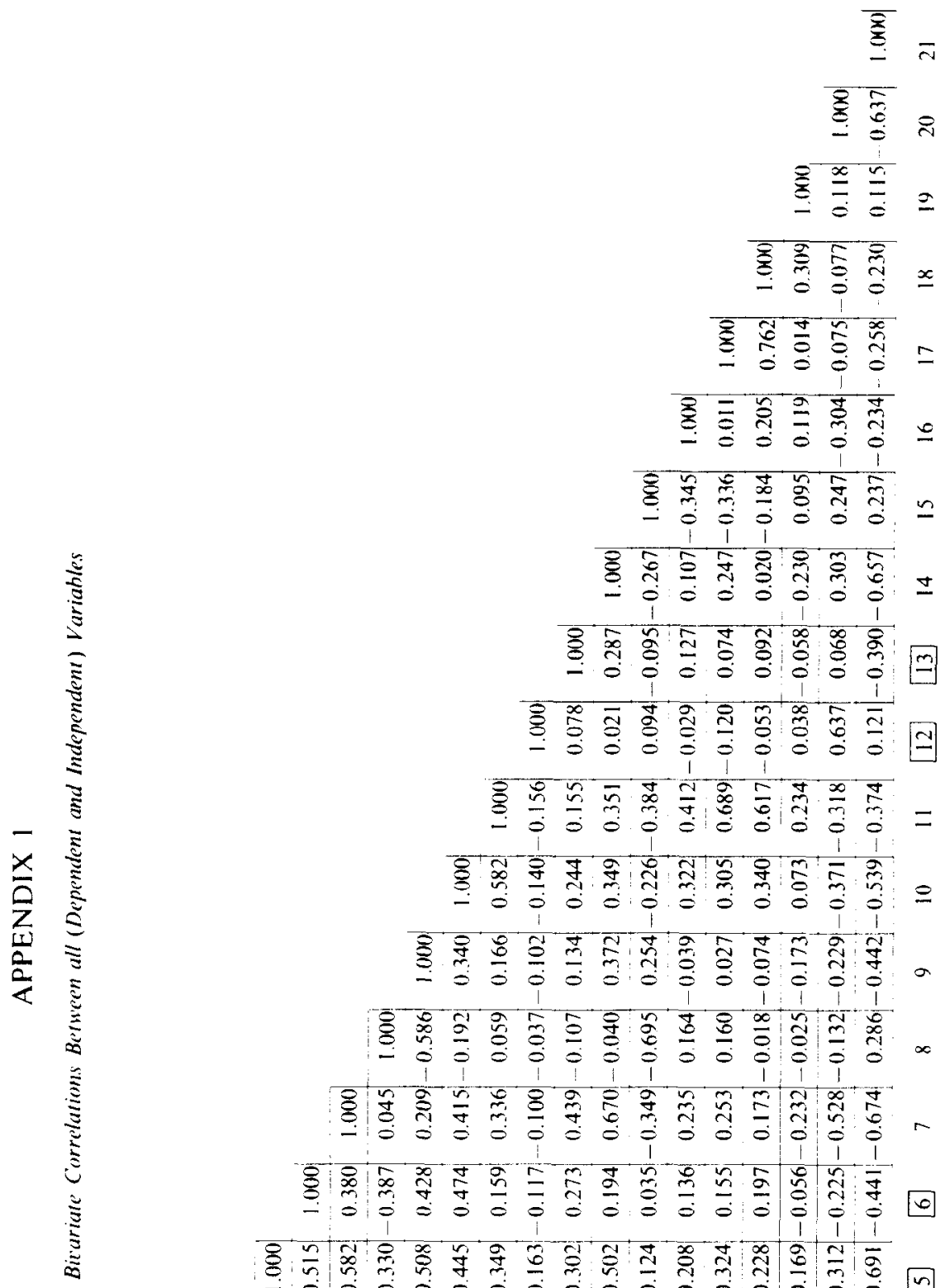

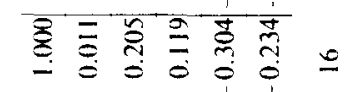

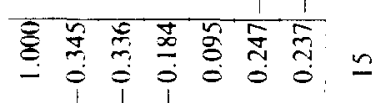

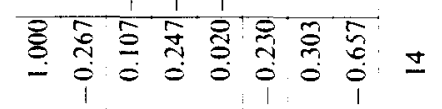

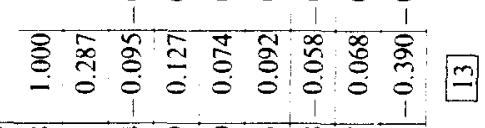

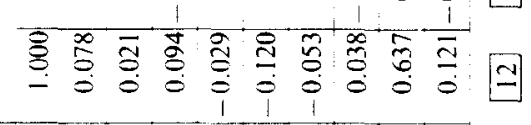

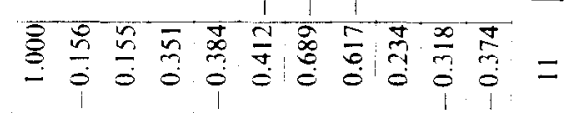

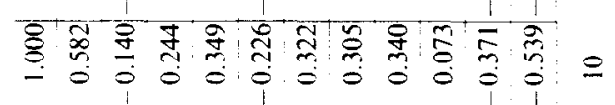

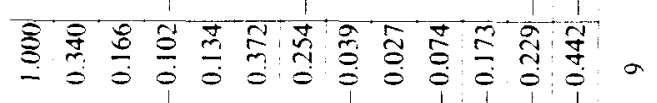

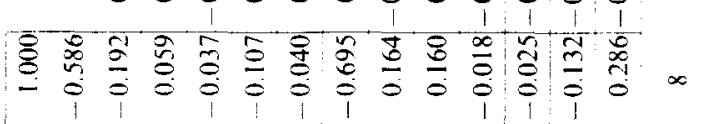

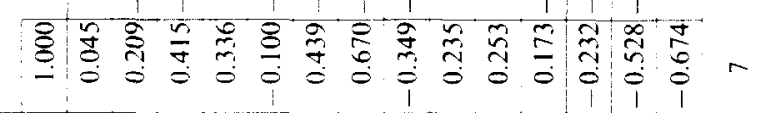

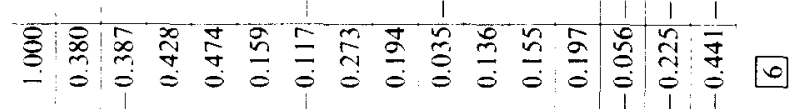

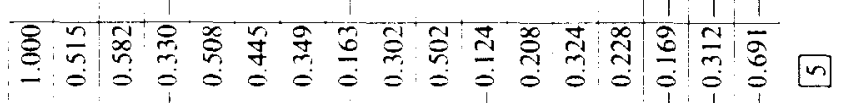

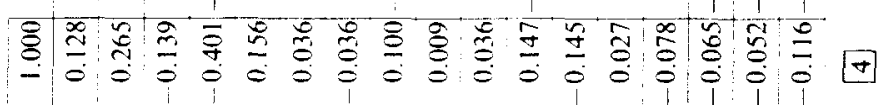

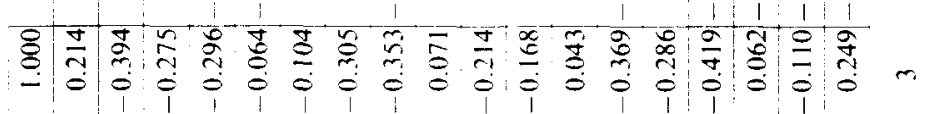

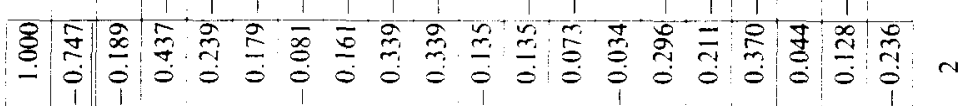

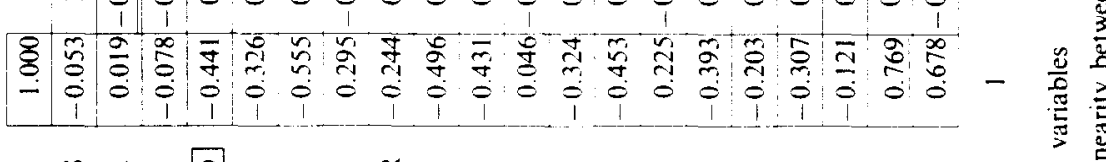

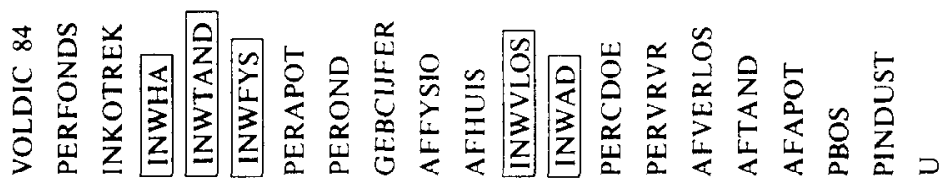

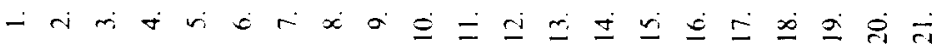




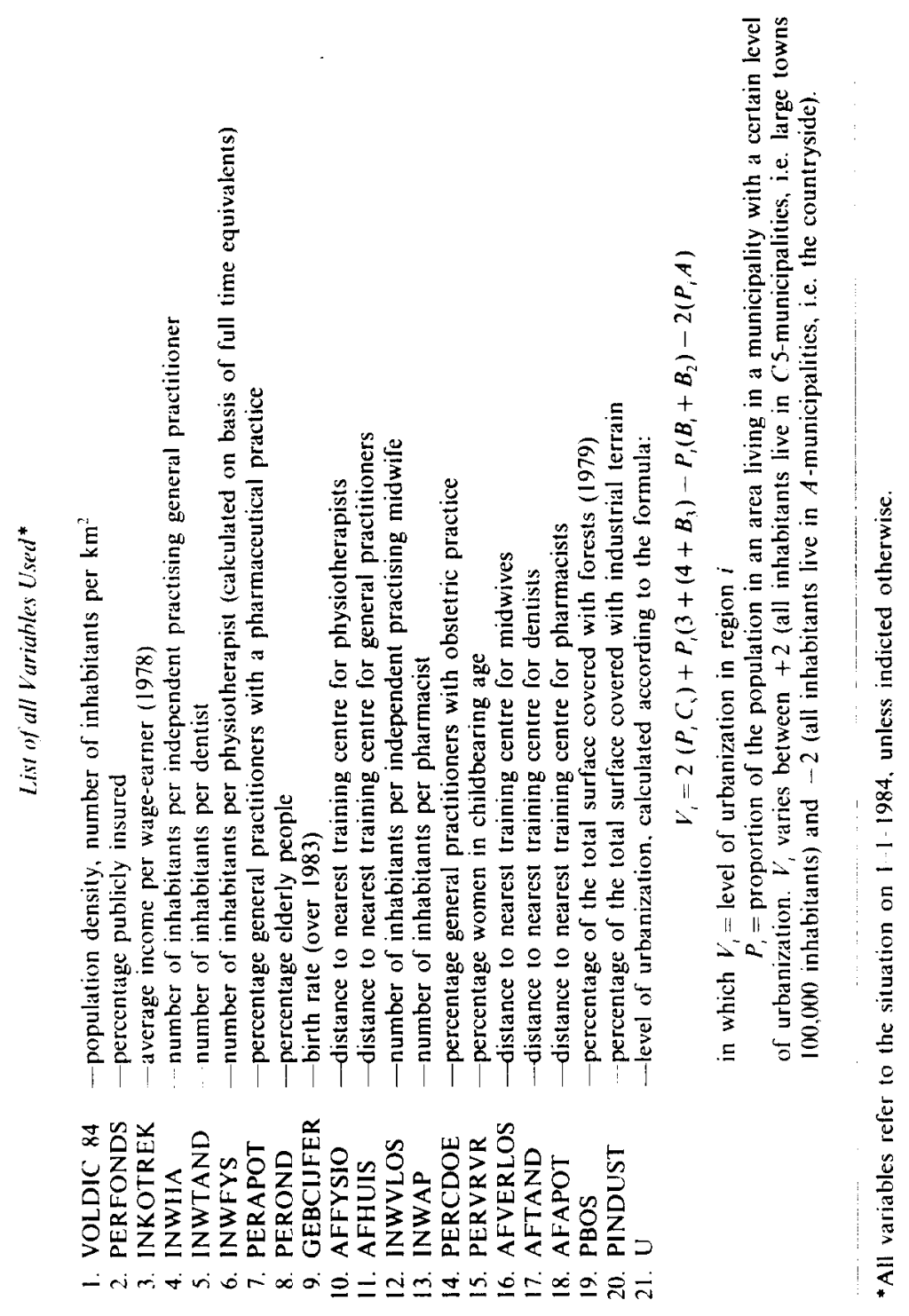

